\title{
Preparation and Characterization of Inorganic Membranes for Hydrocarbon Separation from $\mathrm{N}_{2}$ for Environmental Applications
}

\author{
Mohammed N. Kajama ${ }^{1}$, Habiba Shehu ${ }^{1}$, Edidiong Okon $^{1} \&$ Edward Gobina ${ }^{1}$ \\ ${ }^{1}$ Centre for Process Integration and Membrane Technology, (CPIMT), School of Engineering, The Robert \\ Gordon University, United Kingdom \\ Correspondence: Edward Gobina, Centre for Process Integration and Membrane Technology, (CPIMT), School \\ of Engineering, The Robert Gordon University, AB10 7GJ, Aberdeen, United Kingdom. Tel: 44-012-2426-2348. \\ E-mail: e.gobina@rgu.ac.uk
}

Received: March 25, 2015

Accepted: April 24, 2015

Online Published: May 20, 2015

doi:10.5539/eer.v5n1p110

URL: http://dx.doi.org/10.5539/eer.v5n1p110

\begin{abstract}
This paper reports the preparation and characterization of a tubular alumina and silica membrane for propylene $\left(\mathrm{C}_{3} \mathrm{H}_{6}\right)$ and nitrogen $\left(\mathrm{N}_{2}\right)$ separation. Dip-coating technique was employed to prepare silica membrane. Nitrogen adsorption measurements reveal that this membrane possesses mesostructure with pore diameter of $3.940 \mathrm{~nm}$ and BET surface of $0.484 \mathrm{~m}^{2} / \mathrm{g}$. Scanning electron microscopy (SEM) studies show that the layers are defect free and energy diffraction X-ray analysis (EDXA) confirms the compositional element of silica. Propylene and nitrogen permeation tests also confirmed that the membrane is defect free with $\mathrm{C}_{3} \mathrm{H}_{6} / \mathrm{N}_{2}$ selectivity of 1.79 higher than ideal Knudsen selectivity.
\end{abstract}

Keywords: mesoporous membranes, silica membranes, nitrogen adsorption, pore size analysis, hydrocarbon separation

\section{Introduction}

Hydrocarbons are among the most common air pollutants expelled from many industrial processes e.g. chemical (Khan \& Ghoshal, 2000), metal cleaning (Huang \& Lin, 1997) among others. The venting of these hydrocarbons to the atmosphere is an enormous contribution to poor air quality. From an environmental point of view, it is imperative to separate these hydrocarbons from waste gas stream. Different countries in the world have regulations in place that tightly regulate these emissions. The United States Environmental Protection Agency proposed the air quality standards of a maximum 3 hour concentration of hydrocarbon content not to exceed 1.6 $x 10^{-4} \mathrm{kgm}^{-3}(0.24 \mathrm{ppm})$ (Ghoshal \& Manjare, 2002). The European community has set a limit not to exceed $35 \mathrm{~g}$ of total organic compounds (TOC) per cubic meter gasoline loaded (Ghoshal \& Manjare, 2002). In addition, the Gothenburg Protocol that was adopted by the EU in 1999 to abate acidification, eutrophication and ground level ozone sets emission levels for sulphur, nitrous oxide, VOCs and ammonia hence, when fully implemented it is expected that European VOC emission will be cut down by $40 \%$ when compared to 1990 levels (Derwent, et al. 2010). In many countries emissions of VOCs and non methane volatile organic compounds (NMVOCs) are not subject to control, hence loss of hydrocarbons into the atmosphere can cause severe environmental pollution and great monetary loss. A number of emerging techniques are being developed as a substitute to more established processes such as absorption, adsorption and condensation and membrane processes (Khan \& Ghoshal, 2000; Huang \& Lin, 1997).

Membrane processes has recently emerged as the state-of-the-art technology for such application. This technique was earlier applied in the last five decades for desalination purposes (Khan \& Ghoshal, 2000), volatile organic compounds (VOC) removal (Khan \& Ghoshal, 2000; Huang \& Lin, 1997; Tahir \& Koh, 1999; Saracco \& Specchia, 2000; Pina, et al., 1996; Pina, et al., 1997; Benard, et al., 2009; Benard, et al., 2010) and natural gas processing (Kajama, et al., 2014). Polymeric membranes such as hollow fibre composite membrane of silicone rubber have been used. Polymeric membranes have very low permeabilities for solvents but their selectivities are quite high (Huang \& Lin, 1997). Indeed, polymeric membranes cannot resist harsh chemical environments and cannot withstand high temperatures. Therefore, ceramic membranes can substitute polymeric membranes since these are chemically resistant and thermally stable. The driving force (partial or total pressure) is the pressure difference across the membrane (Vercauteren et al., 1998). Gas transport mechanisms through porous membrane 
include: surface diffusion, Knudsen diffusion, capillary condensation, Poiseuille or viscous flow, and molecular sieving mechanisms (Coronas \& Santamaria, 1999; Lee \& Oyama, 2002; Sidhu \& Cussler, 2001). In Knudsen diffusion mechanism, gas molecules diffuse through the pores of the membrane and then get transported by colliding more frequently with the pore walls (Lee \& Oyama, 2002; Phattaranawik, et al, 2003), Knudsen mechanism also occurs if the mean free path $(\lambda)$ of the permeating gas molecule is greater than pore diameter (d). This indicates that the Knudsen number $(K)$ is greater than 1 , i.e. $K=\lambda / d>1$ (Sidhu \& Cussler; 2001). Viscous flow mechanism takes place if the pore radius of the membrane is greater than the mean free path of the permeating gas molecule (Lee, et al. 2005; Benito, et al. 2005). Gas separation by molecular sieving mechanism takes place when the pore dimensions of the inorganic ceramic membrane approach those of the permeating gas molecules (Li, 2007; and Lee, et al. 2005). In capillary condensation mechanism, separation can takes place in the pores of the membrane with mesoporous layer in the presence of condensable gas specie. Surface diffusion mechanism occurs when the adsorption of the permeating gas molecule occurs on the pore surface of the membrane material there by increasing the gas transport performance (Lee, et al. 2005; Javaid, et al. 2005).

Uhlhorn, et al. $(1990 ; 1992)$ used gamma alumina $\left(\gamma-\mathrm{Al}_{2} \mathrm{O}_{3}\right)$ membranes with a pore diameter of $2.5 \mathrm{~nm}$ and magnesium oxide $(\mathrm{MgO})$ modified membranes with a lower pore size in order to separate propene from nitrogen $\left(\mathrm{C}_{3} \mathrm{H}_{6} / \mathrm{N}_{2}\right)$ mixtures. The membranes recorded both permeabilities and separation factors higher than those for Knudsen diffusion.

The characterization of porous ceramic membranes is typically elaborated by the flux and the selectivity which are influenced by the pore size distribution, intrinsic membrane surface properties and porosity (Smart, et al. 2013). According to the International Union of Pure and Applied chemistry (IUPAC) definition, membranes pores structure are classified as mesoporous $(2-50 \mathrm{~nm})$, microporous $(<2 \mathrm{~nm})$ and macroporous $(>50 \mathrm{~nm})$ layers. Porous metallic membranes with the pore size greater than $0.3 \mathrm{~nm}$ are normally used as sieves for larger molecules and particles (Li, 2007; Guizard \& Princivalle, 2009; Ismail \& David, 2011).

Scanning electron microscopy (SEM) is a technique used to analyse the morphological surface of the membrane and their cross-sections. It can also be employed for high magnification of the membrane separation layer. Energy diffraction x-ray analysis (EDXA) is used to analyze the elemental compositions of the membrane. $\mathrm{N}_{2}$ adsorption-desorption isotherm $(77 \mathrm{~K})$ is a standard technique employed to characterize the pore structure and network of a material. It is perhaps simple and the most widely used method to determine the specific surface area, pore size and pore size distribution for meso and micro porous adsorbents (Smart, et al. 2013; Choma, et al. 2003). The gas adsorption isotherm is divided into six categories (Smart, et al. 2013; Choma, et al. 2003; Weidenthaler, 2011). Five of the six categories are mentioned in the IUPAC recommendations (Choma, et al. 2003).

Type I isotherm is governed by adsorption in micropores sample (with $<2 \mathrm{~nm}$ pore size) at low relative pressure, while Type II isotherm is regarded as a non-porous or macroporous (with $>50 \mathrm{~nm}$ pore size) adsorbents formation of multilayers of adsobate on surfaces of adsorbent. Type III isotherm is also a non-porous or macroporous adsorbents with weak adsorbent-adsorbate interactions. Type IV isotherm is a typical mesoporous adsorbents with initial monolayer-multilayer coverage on external and mesopore surface and is followed by capillary condensation in mesopores with different types of hysteresis loops which are observed depending on the shape of pores. Type $\mathrm{V}$ isotherm is also a mesoporous adsorbents with weak adsorbent-adsorbate interactions. An example of this uncommon isotherm is observed for water adsorption on activated carbon (Weidenthaler, 2011). Type VI isotherm is a highly uniform surface which shows a layer-by-layer adsorption (Smart et al. 2013; Choma et al. 2003; Weidenthaler, 2011).

In this study, the permeation of propylene and nitrogen through silica membrane were carried out at various pressures as the driving force and ambient temperature. $\mathrm{N}_{2}$ sorption at $77 \mathrm{~K}, \mathrm{SEM}$ and EDXA were employed for membrane characterization.

\section{Experimental}

\subsection{Membrane Support}

Commercially available porous alumina supports of tubular configuration supplied by CTI (France) consisted of $77 \%$ alumina $+23 \% \mathrm{TiO}_{2}$ were employed for this experiment. The tubular alumina support used for this experiment is depicted in Figure 1. The alumina support had an internal and outer diameter of 7 and $10 \mathrm{~mm}$ respectively with a permeable length of $348 \mathrm{~mm}$ and a porosity of $45 \%$. 


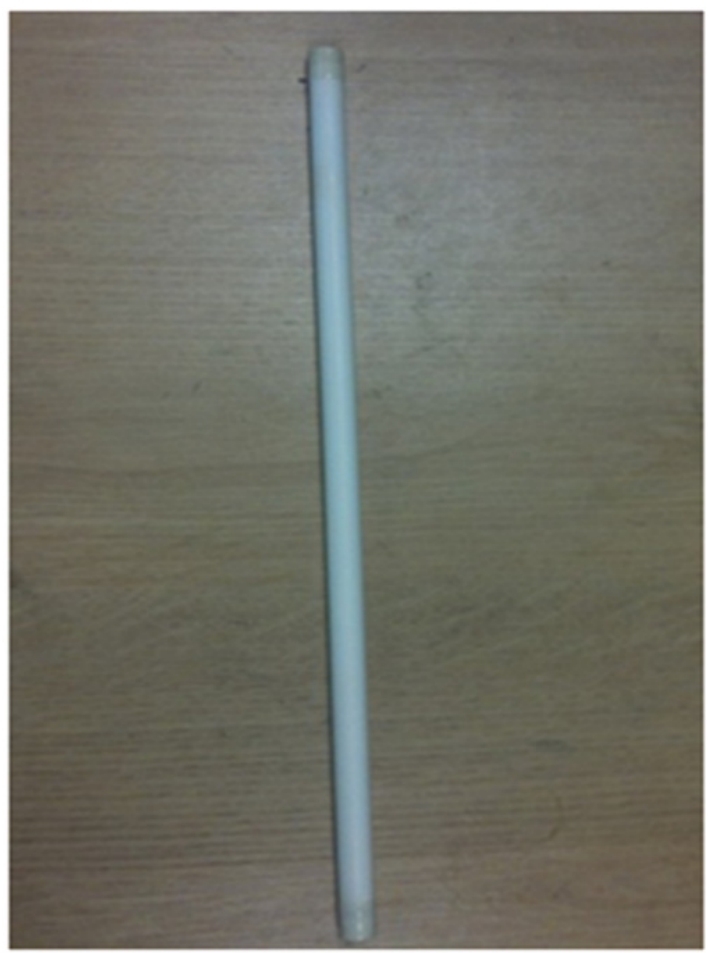

Figure 1. Commercial tubular ceramic support

Pressures of 0.05 to 0.45 barg and temperatures of $22{ }^{\circ} \mathrm{C}(295 \mathrm{~K})$ were applied. Crushed samples of the unmodified and modified membranes (Figure $2 \mathrm{a}$ and $\mathrm{b}$ ) were used for characterization (nitrogen adsorption and scanning electron microscopy respectively).
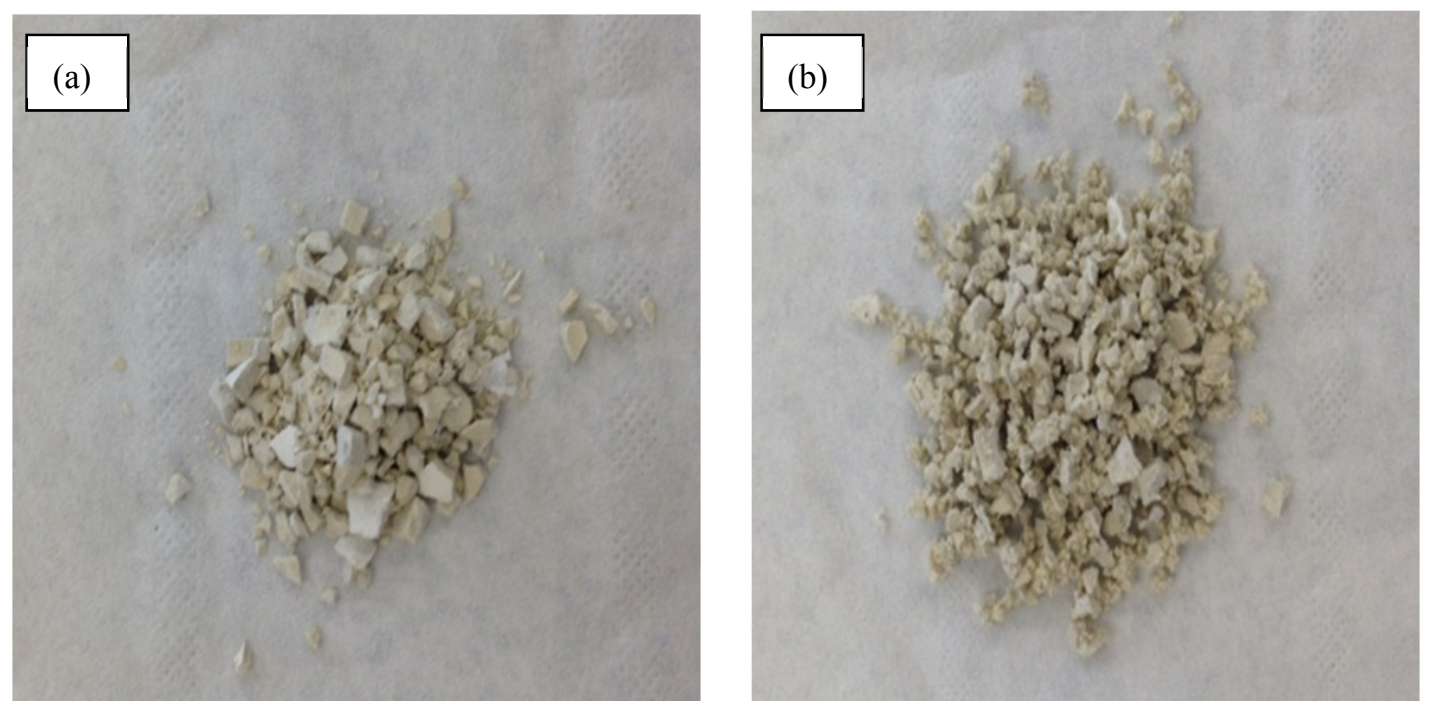

Figure 2 (a). Crushed sample of the support (unmodified), (b). Crushed sample of silica membrane (modified)

\subsection{Membrane Preparation}

The solution use for membrane preparation was prepared by mixing $50 \mathrm{ml}$ of silicone elastomer (Sylgard ${ }^{\circledR}$ ) and nine parts of isopentane contained in a glass tube to obtain a clear and colourless solution. A curing agent $\left(\operatorname{Sylgard}^{\mathbb{B}}\right)$ equivalent to one-tenth of the elastomer was added and the resulting solution was mixed at room temperature. The solution was then allowed to age for 30 minutes after which the ceramic support was immersed for 30 minutes. The membrane was then oven dried at $65^{\circ} \mathrm{C}$ for 24 hours (Gobina, 2006; Nwogu, et al. 2013) to form an ultra-thin layer on the support. The same procedure was repeated for subsequent coatings. 


\subsection{Membrane Characterization}

The Brunauer-Emmett-Teller (BET) method for surface area, Barrett-Joyner-Helanda (BJH) method for pore size distribution, and the adsorption-desorption isotherm of unmodified support and silica modified membrane were obtained from $\mathrm{N}_{2}$ sorption isotherm (Quantachrome instrument version 3.0). Prior to $\mathrm{N}_{2}$ sorption analysis, weighted crushed samples were degassed for $180 \mathrm{~min}$ at $300{ }^{\circ} \mathrm{C}$ at a rate of $10{ }^{\circ} \mathrm{C} / \mathrm{min}$. The inner, outer and cross-sectional surface morphologies of the support and membrane were analyzed by SEM (Zeiss EVO LS10). The support was found to be defect free. EDXA was also employed to analyze the elemental compositions of the material before and after modification.

\subsection{Gas Permeation Measurements}

Permeation behaviour of pure gases nitrogen $\left(\mathrm{N}_{2}\right)$ and propylene $\left(\mathrm{C}_{3} \mathrm{H}_{6}\right)$ were measured at different feed pressures ranging from 0.05 to 0.45 bar. Permeate readings were recorded as $1 / \mathrm{min}$ at ambient temperature.

\section{Results and Discussion}

\subsection{Structure of Unmodified and Modified Membranes}

Figure 3( $a$ and $b$ ) depicts the SEM images of the inner and outer surface of the unmodified membrane. The images exhibit a defect free support. Figure 4(a and b) depicts the inner and outer surface of the silica modified membranes. It can be seen in Figure 4(b) that ultra-thin layer was formed on the outer surface of the membrane and the silica layer is clearly visible from the micrograph. From this image, one can see a good bonding to the support without any pinholes on the layer.

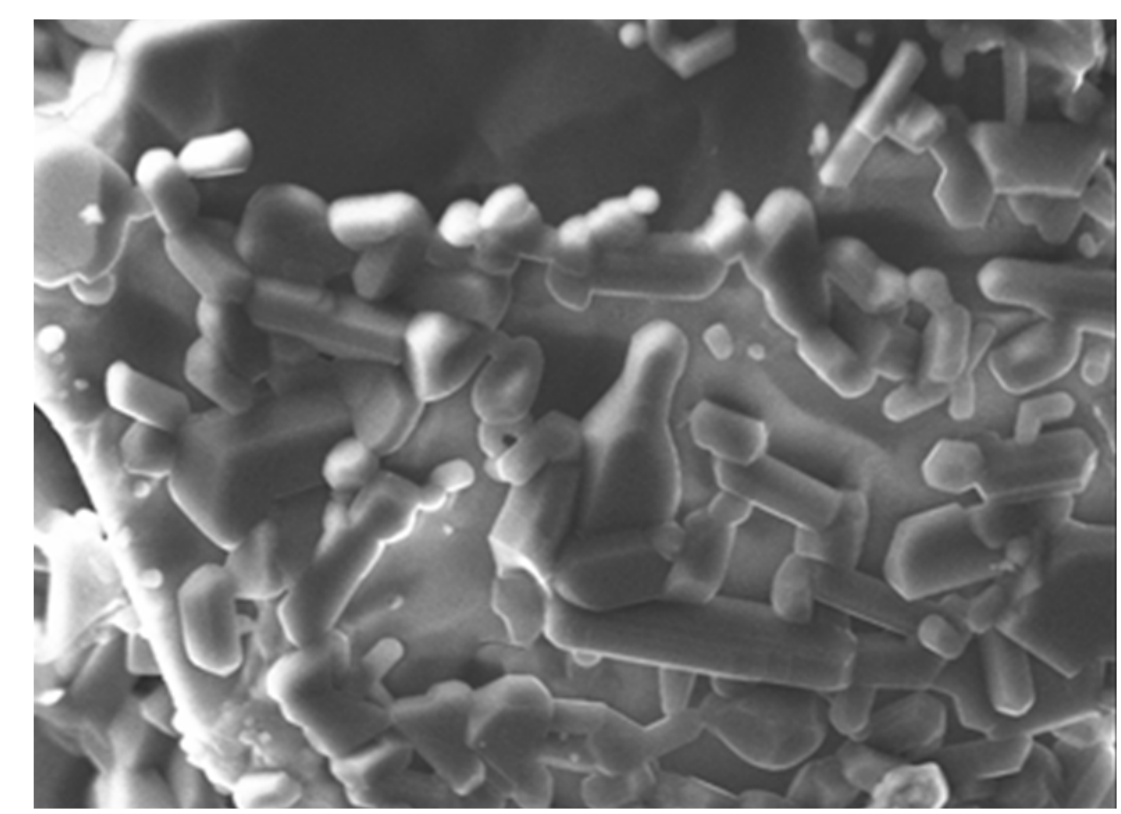

Figure 3(a). SEM image of the support (unmodified) inner surface 


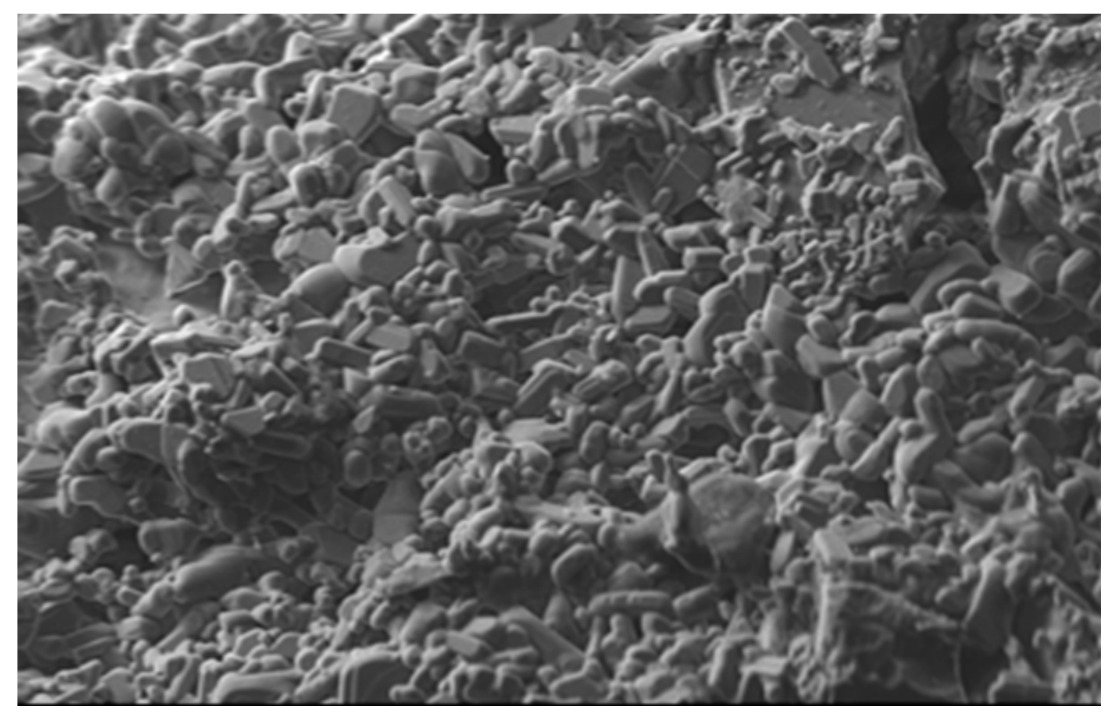

Figure 3(b). SEM image of the support (unmodified) outer surface

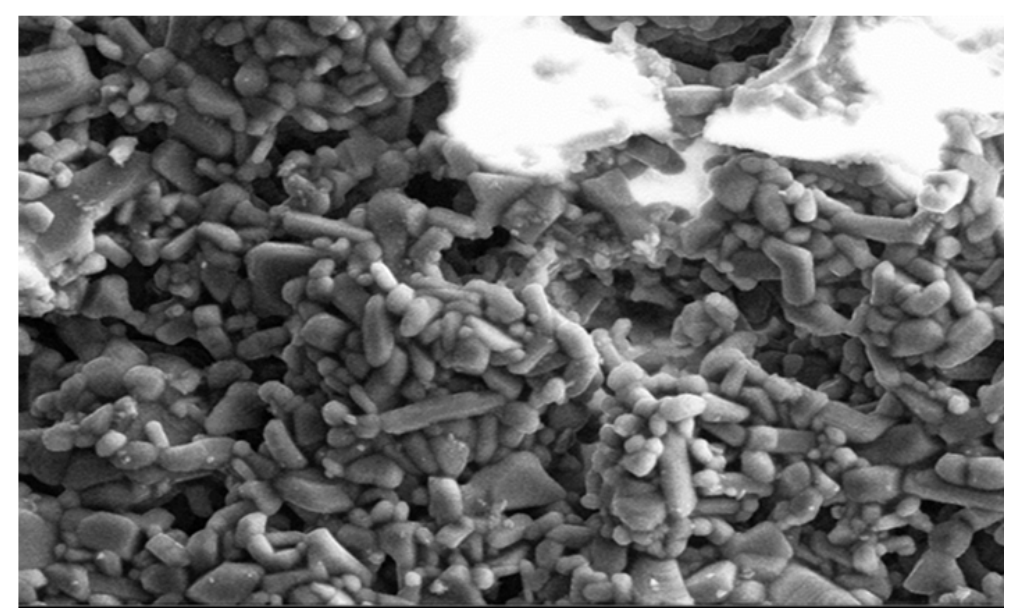

Figure 4(a). SEM image of silica membrane (modified) inner surface

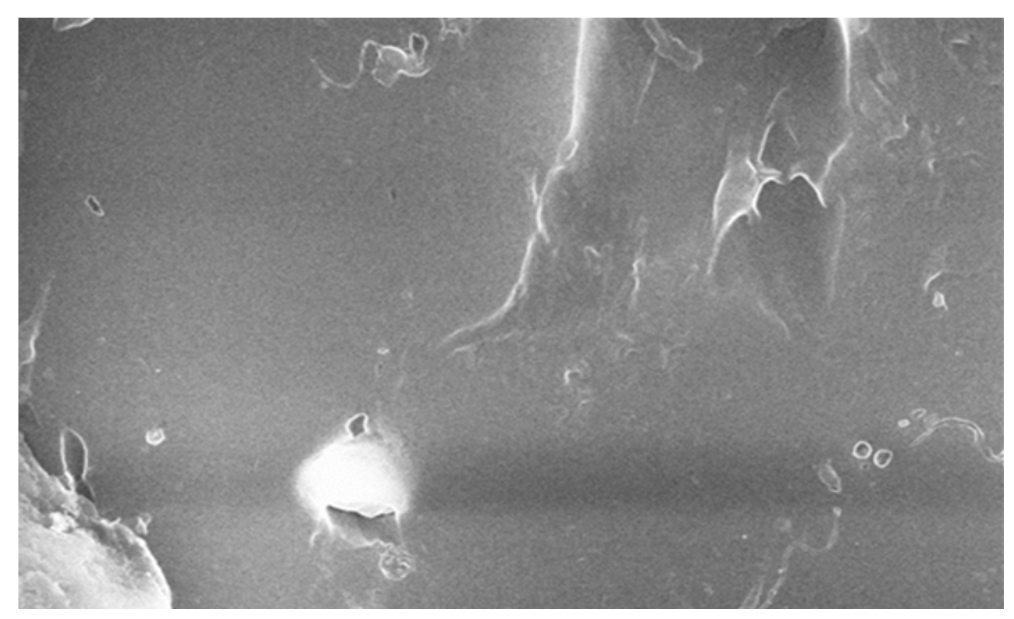

Figure 4(b). SEM image of silica membrane (modified) outer surface

Figures 5(a and b) \& Figure 6(a and b) depicts the EDX analysis for unmodified and modified membrane. These Figures show the elemental compositions of the membrane before and after modification. It can be obviously seen in Figure 5( $a$ and $b$ ) that there was no sign of silica particle before modification. However, silica particles 
were observed after modification as indicated on the EDXA result in Figure 6(b).

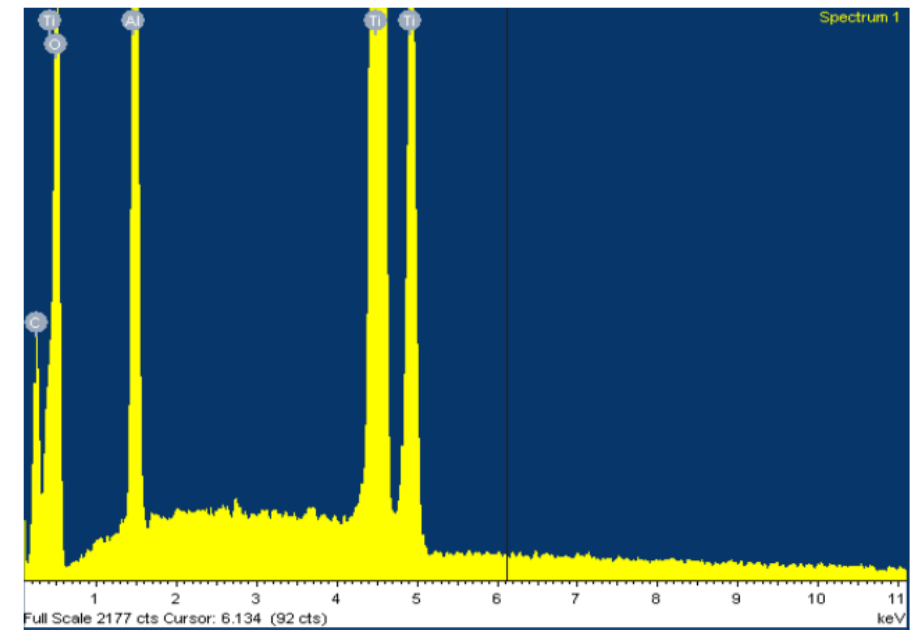

Figure 5(a). EDXA of the support (unmodified) inner surface

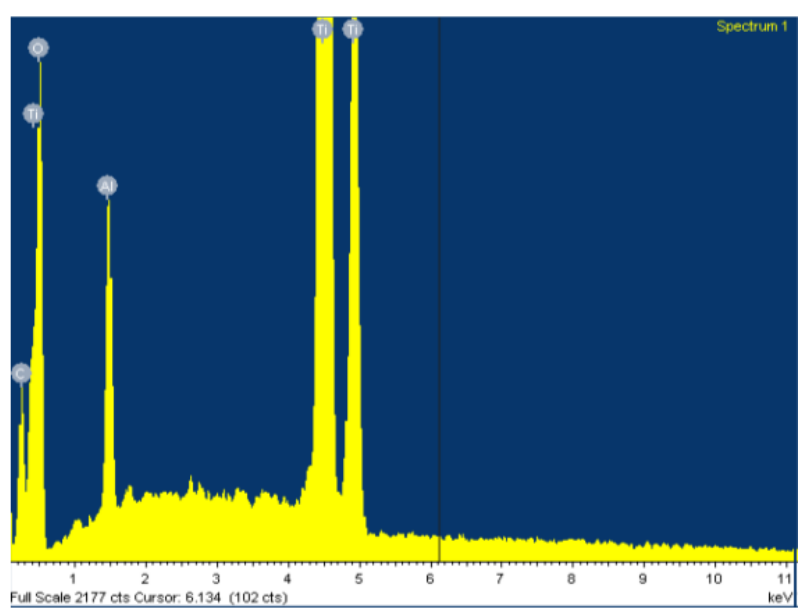

Figure 5(b). EDXA of the support (unmodified) outer surface

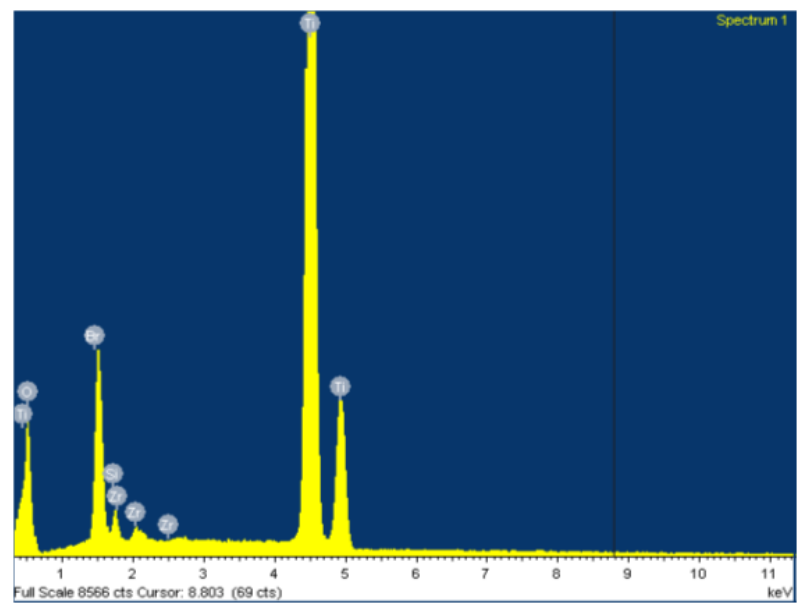

Figure 6(a). EDXA of silica membrane (modified) inner surface 


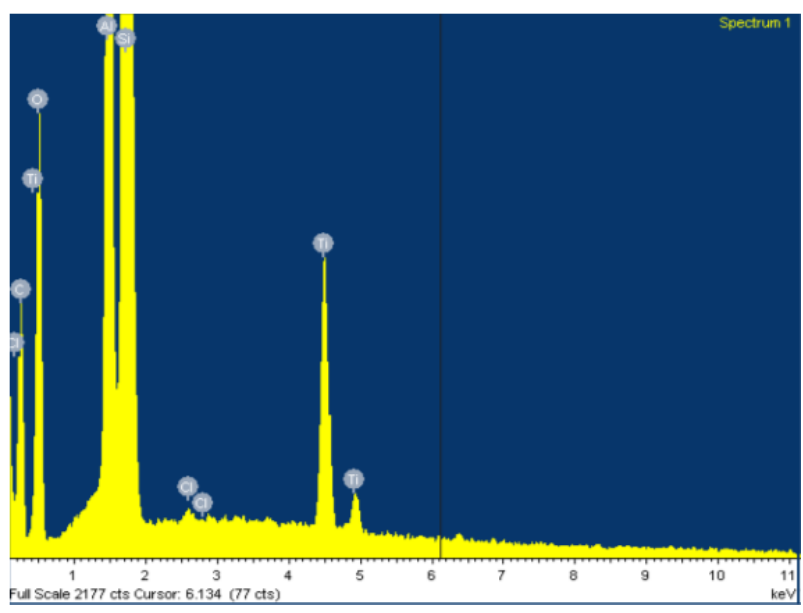

Figure 6(b). EDXA of silica membrane (modified) outer surface

Figure 7(a and b) \& Figure 8( $\mathrm{a}$ and $\mathrm{b})$ depicts the $\mathrm{N}_{2}$ adsorption-desorption isotherms of unmodified and silica modified membranes. The adsorption-desorption isotherms exhibits a characteristics of mesopores solids (especially ceramics) resulting in type IV and V physisorption isotherm undergoing capillary condensation and hysteresis during desorption (Smart, et al. 2013). Different parameters were obtained for the Brunauer-Emmett-Teller (BET) method surface area and Barrett-Joyner-Helanda (BJH) method pore size distribution. Table 1 quantitatively shows the physical properties obtained with nitrogen adsorption for the unmodified alumina support and modified silica membrane. The BET surface area and BJH pore diameter were $0.364 \mathrm{~m}^{2} / \mathrm{g}$ and $4.171 \mathrm{~nm}$ for the unmodified support and $0.439 \mathrm{~m}^{2} / \mathrm{g}$ and $4.179 \mathrm{~nm}$ for the modified membrane respectively. BET surface area increased to about $0.484 \mathrm{~m}^{2} / \mathrm{g}$ after subsequent dipping. BJH pore diameter also decreased from 4.171 to $3.940 \mathrm{~nm}$ which indicates that some amount of silica has penetrated into the support pores which shows a typical mesopore diameter in the range 2 to $50 \mathrm{~nm}$. This is consistent with the above SEM and EDXA results.

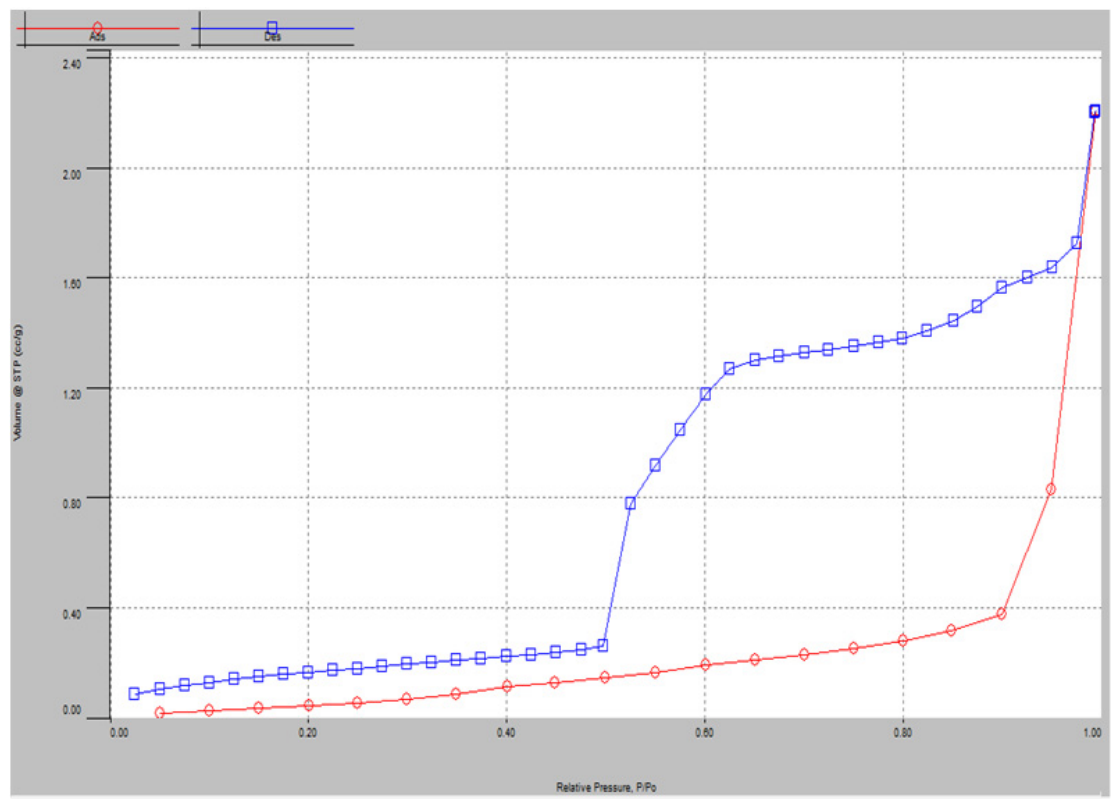

Figure 7(a). $\mathrm{N}_{2}$ adsorption-desorption isotherm for the support (unmodified) 


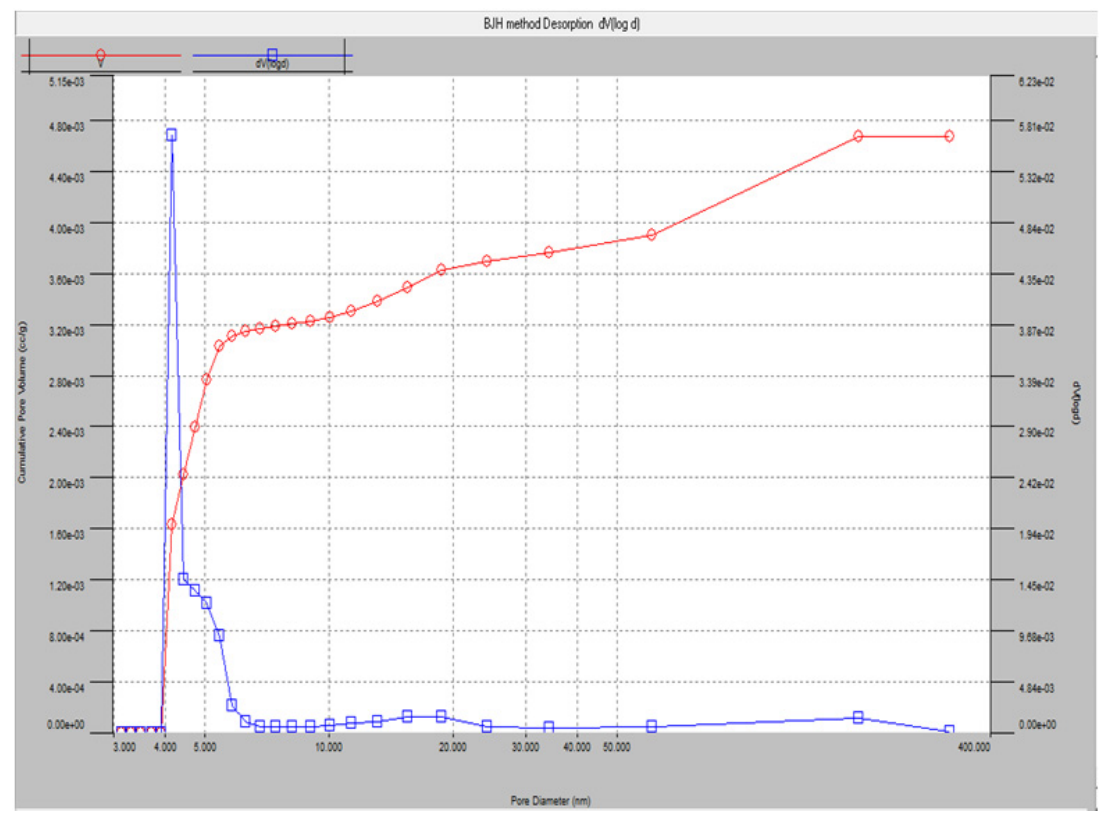

Figure 7(b). Pore size distribution for the support (unmodified)

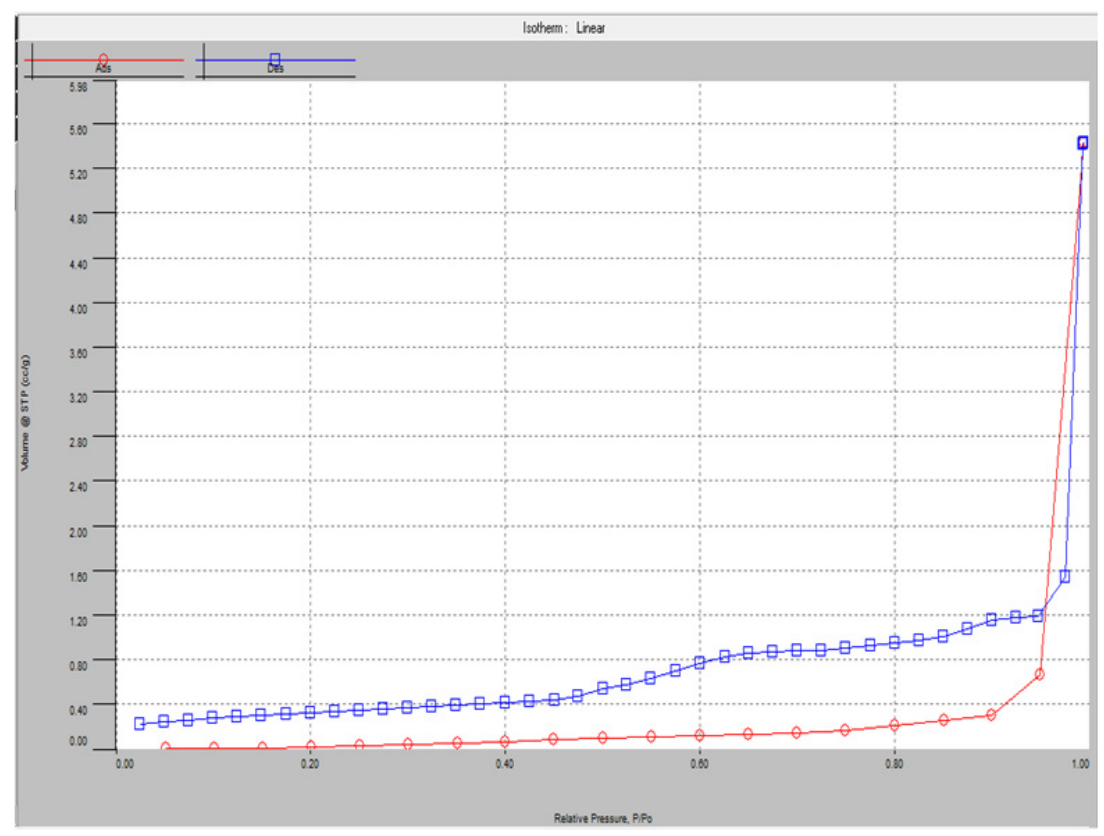

Figure $8(a) . \mathrm{N}_{2}$ adsorption-desorption isotherm for the silica membrane (modified) 


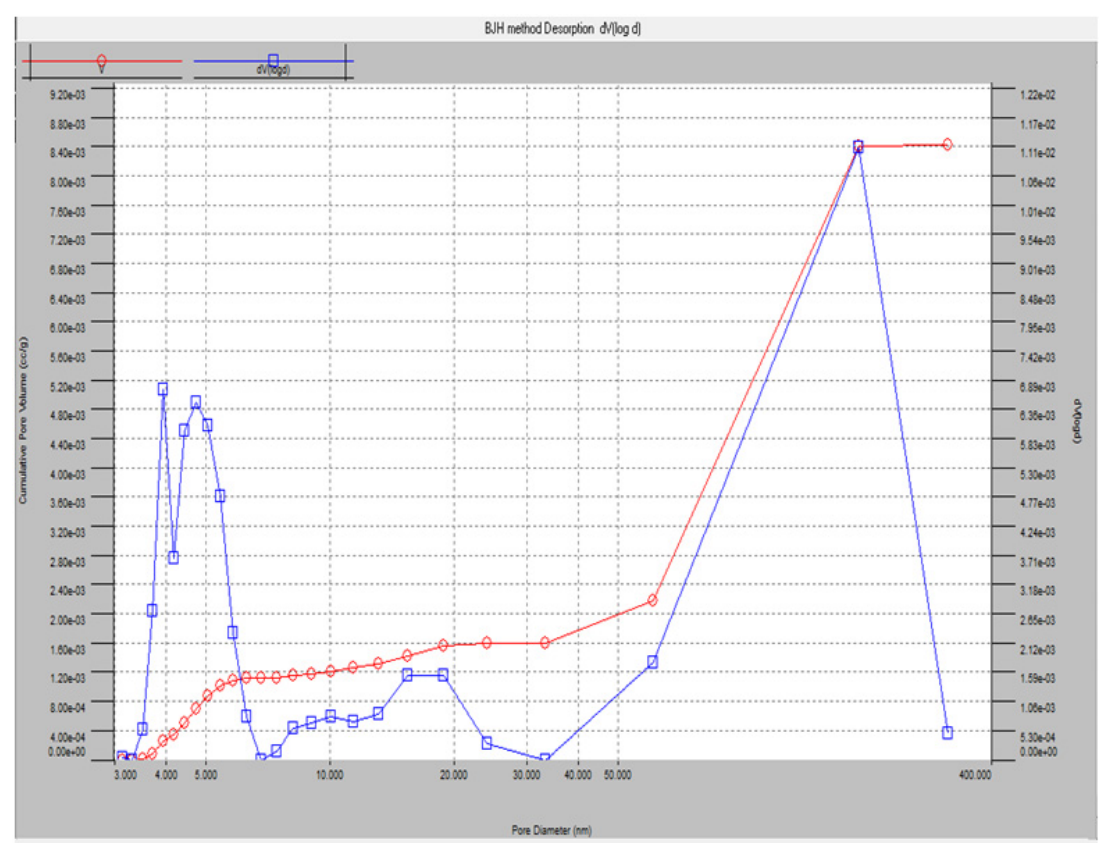

Figure $8(b)$. Pore size distribution for the silica membrane (modified)

Table 1. Physical properties for unmodified and modified membranes

\begin{tabular}{|c|c|c|}
\hline Membrane & BET surface area $\left(\mathrm{m}^{2} / \mathrm{g}\right)$ & BJH pore diameter $(\mathrm{nm})$ \\
\hline Unmodified Ceramic Support & 0.364 & 4.171 \\
\hline Silica Modified Membrane (5 $5^{\text {th }}$ Dip) & 0.439 & 4.179 \\
\hline Silica Modified Membrane ( $9^{\text {th }}$ Dip) & 0.484 & 3.940 \\
\hline
\end{tabular}

\subsection{Nitrogen and Propylene Permeation}

Figure 9 depicts gas flow rate through silica membrane as a function of the feed pressure at room temperature. Nitrogen and propylene gas flow rates increases with the feed pressure. It can be seen that propylene has the higher flow rate compared to nitrogen despite its higher molecular weight $\left(\mathrm{N}_{2}: 28 \mathrm{~g} / \mathrm{mol} ; \mathrm{C}_{3} \mathrm{H}_{6}: 42 \mathrm{~g} / \mathrm{mol}\right)$. This result is consistent with the contribution of surface flow mechanism. Figure 10 shows the selectivity of $\mathrm{C}_{3} \mathrm{H}_{6}$ over $\mathrm{N}_{2}$. Highest selectivity of 1.79 at 0.05 barg was obtained. This selectivity increased by a factor of 2 compared to the ideal Knudsen selectivity (0.82) which corroborates with the literature Uhlhorn, et al. (1990; 1992). From the obtained gas permeation and selectivity, one can conclude that hydrocarbon could be separated from nitrogen.

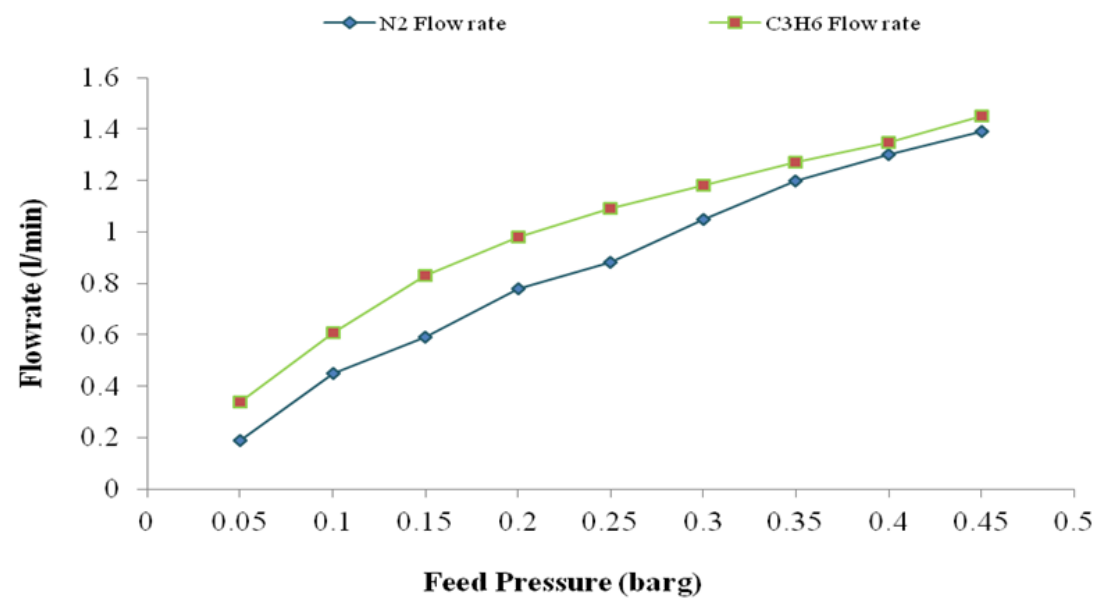

Figure 9. Gas flow rates of nitrogen and propylene as a function of feed pressure at room temperature 


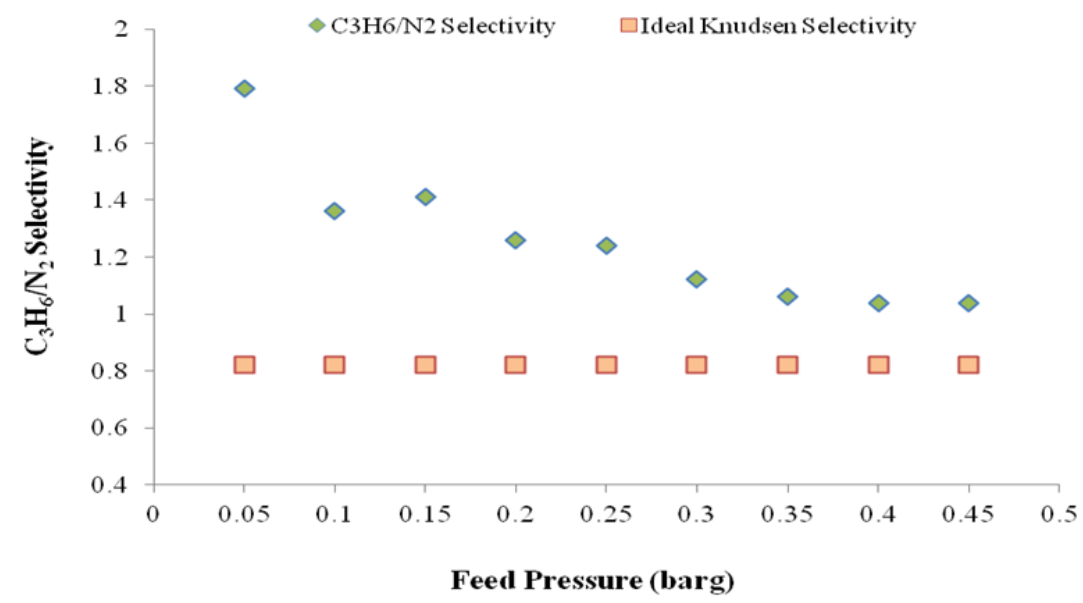

Figure $10 . \mathrm{C}_{3} \mathrm{H}_{6} / \mathrm{N}_{2}$ selectivity as a function of feed pressure at room temperature

\section{Conclusion}

Defect-free mesoporous silica membrane has been developed on the alumina substrate by dip-coating technique. The BET surface area and BJH pore diameter of the membrane are $0.484 \mathrm{~m}^{2} / \mathrm{g}$ and $3.940 \mathrm{~nm}$ respectively. The prepared membrane was defect free as confirmed by the propylene and nitrogen permeation data. The high propylene selectivity obtained at low pressure drop is indicative of selective surface flow mechanism. Work is currently being carried out to compare mixed gas selectivity to pure gas selectivity.

\section{Acknowledgments}

The authors gratefully acknowledge Petroleum Technology Development Fund (PTDF) Nigeria for funding this research and School of Pharmacy \& Life Sciences RGU Aberdeen for the SEM and EDXA results.

\section{References}

Benard, S., Giroir-Fendler, A., Vernoux, P., Guilhaume, N., \& Fiaty, K. (2010). Comparing monolithic and membrane reactors in catalytic oxidation of propene and toluene in excess of oxygen. Catalysis today, 156, 301-305. http://dx.doi.org/10.1016/j.cattod.2010.07.019

Benard, S., Ousmane, M., Retailleau, L., Boreave, A., Vernoux, P., \& Giroir-Fendler, A. (2009). Catalytic removal of propene and toluene in air over noble metal catalyst ${ }^{1}$. Can. J. Civ. Eng., 36, 1935-1945. http://dx.doi.org/10.1139/L09-135

Choma, J., Kloske, M., \& Jaroniec, M. (2003). An improved methodology for adsorption characterization of unmodified and modified silica gels. Journal of Colloid and Interface Science, 266, 168-174. http://dx.doi.org/10.1016/S0021-9797(03)00573-3

Gobina, E. Apparatus and Methods for Separating Gases. (2006). United States Granted Patent No. US 7048778, May 23, 2006.

Huang, P., Xu, N., Shi, J., \& Lin, Y. S. (1997). Recovery of volatile organic compounds from air by ceramic membranes. Ind. Eng. Chem. Res., 36, 3815-3820. http://dx.doi.org/10.1021/ie960760b

Kajama, M. N., Nwogu, N. C., \& Gobina, E. (2014). Hydrogen Separation Using Silica-Based Composite Membranes. Advanced Materials Research, Trans Tech Publications, 1051, 107-111. http://dx.doi.org/10.4028/www.scientific.net/AMR.

Khan, F. I., \& Ghoshal, A. K. (2000). Removal of volatile organic compounds from polluted air. Journal of Loss Prevention in the Process Industries, 13, 527-545. http://dx.doi.org/10.1016/S0950-4230(00)00007-3

Nwogu, N. C., Gobina, E., \& Kajama, M. N. (2013). Improved carbon dioxide capture using nanostructured ceramic membranes. Low Carbon Economy, 4, 125-128. http://dx.doi.org/10.4236/lce.2013.43013

Pina, M. P., Irusta, S., Menendez, M., \& Santamaria, J. (1997). Combustion of Volatile Organic Compounds over Platinum-Based Catalytic Membranes. Industrial Engineering Chemistry Resources, 36, 4557-4566. http://dx.doi.org/10.1021/ie9700876

Pina, M. P., Menendez, M., \& Santamaria, J. (1996). The Knudsen-diffusion catalytic membrane reactor: An 
efficient contactor for the combustion of volatile organic compounds. Applied Catalysis B: Environmental, 11, L19-L27. http://dx.doi.org/10.1016/S0926-3373(96)00081-1

Saracco, G., \& Specchia, V. (2000). Catalytic Filters for the Abatement of Volatile Organic Compounds. Chemical Engineering Science, 55(5), 897-908. http://dx.doi.org/10.1016/S0009-2509(99)00361-9

Smart, S., Liu, S., Serra, J. M., Diniz da Costa, J. C., Iulianelli, A., \& Basile A. (2013). Porous ceramic membranes for membrane reactors. http://dx.doi.org/10.1533/9780857097330.2.298

Tahir, S. F., \& Koh, C. A. (1999). Catalytic destruction of volatile organic compound emissions by platinum based catalyst. Chemosphere, 38(9), 2109-2116. http://dx.doi.org/10.1016/S0045-6535(98)00420-2

Uhlhorn, R. J. R., Keizer, K., \& Burggraaf, A. J. (1990). Gas transport and separation properties of ceramic membranes with pores of molecular dimensions. Paper presented at the International Congress on membranes and membrane processes (ICOM 90), Chicago, IL, August 1990.

Uhlhorn, R. J. R., Keizer, K., \& Burggraaf, A. J. (1992). Gas transport and separation with ceramic membranes Part 1, Multilayer diffusion and capillary condensation. J. Membrane Science, 66, 259-269.

Weidenthaler, C. (2011). Pitfalls in the characterization of nanoporous and nanosized materials. Nanoscale, 3, 792-810. http://dx.doi.org/10.1039/C0NR00561D

\section{Copyrights}

Copyright for this article is retained by the author(s), with first publication rights granted to the journal.

This is an open-access article distributed under the terms and conditions of the Creative Commons Attribution license (http://creativecommons.org/licenses/by/3.0/). 